\title{
The Problems and Countermeasures of Real Estate Economy in China
}

\author{
You-Lian Guo \\ Tianjin Vocational Institute, Tianjin, China \\ Email: guoyoulian2010@163.com
}

\begin{abstract}
- the real estate industry is the pillar industry of Chinese national economy. The main problems existed in the real estate economy in China: Chinese real estate bubble serious; local fiscal revenue over reliance on real estate construction waste of land resources; Structural imbalance between supply and demand of real estate commercial housing. In view of the problems put forward countermeasures: developing the real economy; increasing the local finance revenue; strengthening supervision of land by law, promoting the development of urbanization with equalization of public resources, curbing the first and second tier cities housing investment demand, increasing the first and second tier cities in the construction of affordable housing.
\end{abstract}

Keywords- real estate, real estate economy, Real estate industry, problems, countermeasures

\section{THE ROLE OF REAL ESTATE ECONOMY IN CHINESE ECONOMY}

A. The Real Estate Industry is the Pillar Industry of the National Economy, Which Plays A Supporting Role In The Development of Chinese Economy.

The real estate industry is the pillar industry of the national economy, which plays a supporting role in the economic development of China. Mainly bases on the contribution rate of the real estate industry to our country's economic growth. According to Meisheng Nie, the National Real Estate Federation of Industry and Commerce Chamber of Commerce, his data show that real estate sector is an important industry of the national economy. In contribution rate is $10.4 \%$ on average, spur economic growth averaged $1 \%$. After the outbreak of the financial crisis of the most critical in 2009, the real estate industry on Chinese economic growth contribution rate of $19.4 \%, 1.77$ percentage points to spur economic growth. According to the National Bureau of Statistics relevant data: only the real estate development to the contribution rate of GDP growth specific figures as follows: contributed 7.3\% to GDP growth in $2004,6.4 \%$ in $2005,5.9 \%$ in $2006,5.9 \%$ in $2007,5.8 \%$ in $2008,13.3 \%$ in $2009,7.9 \%$ in $2010,7.5 \%$ in $2011,8.8 \%$ in $2012,9.3 \%$ in 2013. It can be seen that: the contribution of real estate development to GDP growth are more than 5.8\% since 2004, 2005-2008 annual average below $6.4 \%$, up to 9.3\% in 2009. 2004 - 2013 real estate development to GDP growth in the average annual contribution rate was $7.8 \%$. Thus further confirms that real estate is an important industry of national economy, is the pillar industry of the national economy, and plays a supporting role in Chinese economic development.

\section{B. The Development of the Real Estate Industry will Lead to the Development of Many Other Industries, and Promote the Contribution to the National Economy.}

Real estate development will lead to the development of many other industries, these industries including building materials industry related to housing construction: cement, steel, glass, metal, metallurgy, ceramics, chemical industry and other manufacturing industries, and housing-related industries, household appliances, furniture, textile and other manufacturing industries, and commercial housing development and sale-related the financial industry and logistics industry development. The development of the real estate industry has promoted the investment of the whole society, which has lead to the additional value of major industry of the national economy. According to the National Bureau of statistics data by the National Bureau of statistics Senior Statistician Division XianchunXu and others arrangement, real estate development and investment promote national economic main industry to increase the value of the case as follows: 
TABLE I. THE REAL ESTATE DEVELOPMENT TO THE CONTRIBUTION RATE OF GDP GROWTH SPECIFIC FIGURES

\begin{tabular}{|l|l|l|}
\hline \multirow{2}{*}{ Industry } & \multicolumn{2}{|c|}{ Value-Added } \\
\cline { 2 - 3 } & 2012 & 2013 \\
\hline \multicolumn{1}{|c|}{ Total } & 43839 & 53848 \\
\hline Primary Industry & 1344 & 1651 \\
\hline Secondary Industry & 32091 & 39418 \\
\hline Construction Industry & 13683 & 16808 \\
\hline Non-metallic Mineral Products Industry & 3382 & 4155 \\
\hline Metal Smelting and Rolling Processing Industry & 2516 & 3090 \\
\hline Coal Mining and Washing Industry & 1634 & 2007 \\
\hline Electricity, Heat Production and Supply Industry & 1478 & 1816 \\
\hline Chemical Industry & 1450 & 1781 \\
\hline General and Special Equipment Manufacturing Industry & 1176 & 1444 \\
\hline Oil and Gas Mining Industry & 1025 & 1259 \\
\hline Petroleum Processing, Coking and Nuclear Fuel Processing & 919 & 1129 \\
\hline Metal Products Industry & 668 & 820 \\
\hline Mining and Dressing Industry of Metal Ores & 652 & 801 \\
\hline Non-Metallic Minerals and Other Mining Industries & 553 & 679 \\
\hline Electrical Machinery and Manufacturing & 536 & 659 \\
\hline Tertiary Industry & 10404 & 12779 \\
\hline $\begin{array}{l}\text { Transportation and Storage Industry Wholesale and Retail } \\
\text { Trade }\end{array}$ & 3220 & 3956 \\
\hline & 2164 & 2659 \\
\hline Finance Industry & 1857 & 2281 \\
\hline Information Transmission, Computer Services and Software & 682 & 837 \\
\hline Industry & & 690 \\
\hline Comprehensive Technical Service Industry & 562 & 673 \\
\hline Accommodation and Catering industry & 548 & \\
\hline
\end{tabular}

Real estate development and investment-led National Economic Value-Added (unit: million)

This shows that the real estate industry led to the development of the national economy

\section{The Real Estate Industry to Promote Economic Growth Driven By The Expansion of the Labor Force is an Important Way to Expand Employment.}

Real estate is an important way to expand employment is mainly reflected in two aspects. On the one hand, in the national economic construction, the first is the modernization of the city, in recent decades, urban construction overall workload increase larger, housing, production and operation of the housing, public infrastructure construction etc, it provides more jobs for construction workers, solve the employment problem of the migrant workers. According to the report data of IMF in July 2013, real estate investment has created at least $14 \%$ of Chinese urban jobs; According to the National Bureau of statistics released data in May 2014, the total amount of migrant workers was 269 million people in 2013, the migrant workers in construction industry ranked first. On the other hand, the real estate industry directly led to the development of financial insurance, leasing and business services, building materials, forestry, light industry, mechanical and electrical industry, and other related industries, the production of products of these industries are inseparable from the manual operation, the rapid development of the industry will demand more labor resources, which will create employment opportunities for the surplus labor force. According to statistics, the proportion of building materials in the construction is more than $40 \%$, especially due to the sustained and rapid development of decoration, making the building materials industry to maintain a high growth rate in a long term. The building materials industry and building decoration industry and the real estate industry association is very strong, while pulling industry will create many jobs. The relationship between financial insurance, leasing and business services and real estateis second only to the relationship between building materials and architectural decoration industry, and the real estate industry development, at the same time, will absorb the financial insurance, leasing and business services employment. Housing construction and use of the light industry, mechanical and electrical drives and other related industries, at the same time, it also create the production of light industrial products and household appliances employment opportunities. The real estate industry driven by the expansion of the labor force is an important way to expand employment. 


\section{The Real Estate Industry to Promote and Accelerate the Construction of Chinese Urbanization.}

First, the urbanization brings incremental space of the real estate industry. According to foreign experience data, when a country's industrialization rate reached $30 \%$, the urbanization rate was $60 \%$; rate reached $70 \%$ and above level of industrialization, urbanization process will stabilize. At present developed countries' urbanization rate was generally around $80 \%$, while the level of agricultural modernization, per income of Malaysia, the Philippines and other countries urbanization rate over $60 \%$, and Chinese industrialization rate nearly $40 \%$, Chinese urbanization lags behind the developed countries, also lags behind the level of its industrialization. In 2012, Chinese urbanization rate reached $52.57 \%$, but the household registration urbanization rate is only $35.29 \%$. In accordance with the laws of the development of word urbanization, Chinese urbanization is still in the range of rapid development. Urbanization brings the industry transfer, mobility, wealth growth, will bring incremental space of the real estate industry. Second, urbanization brings a huge amount of demand for housing. According to the United Nations the UN in the "urban prosperity of 2012/2013", predicts that by 2030, the most conservative estimate there will be 250 million people into the city, a neutral estimated there will be 270 million people into the city, optimistic estimates there will be 300 million people into the city. These new urban population will bring a huge amount of demand for housing. Third, Chinese per living standards have a clear rise in space. According to the Ministry of Construction Policy Research Center released the" 2020 what kind of house we live --China's comprehensive well-off society living target research", Chinese is expected to achieve per urban housing area of 35 square meters of residential targets in 2020. The future of Chinese per urban residential area still has some room for improvement, the real estate market still has a great potential for development. In addition, the upgrading of urban construction, the improvement of infrastructure, the construction of Metropolitan Suburbs will be the first to promote by the real estate industry.

\section{II.THE MAIN PROBLEMS OF REAL ESTATE ECONOMY IN CHINA}

\section{A. There are Serious Real Estate Bubbles in China.}

China's real estate bubble serious current presence, real estate bubble refers to a phenomenon that the real estate market transaction price caused by long-term rapid rise in the real estate market is far more than the real value. Due to the low profit of the real economy, too high profits of real estate, lead to banks, businesses large amounts of money to invest in real estate, a large amount of money out of the other entity economic into the real estate market, caused the abnormal rise in prices significantly exceeded the actual economic growth level, is beyond the people's ability to pay. Housing price to income ratio serious departure from the reasonable interval, the ratio of the house prices and annual family income of urban residents, usually for 3-6 times for reasonable international area, at present our country the actual housing price to income than the average for 9-10 times, first and second tier cities reached 15 times, more than 20 times in Beijing. According to the National Bureau of statistics relevant data, in the past decade, Chinese house prices continued to rise in most of the time (except for a few quarters). According to the house prices data that we use (started in 2004), 2004 - 2013, the nominal house prices rose $136 \%$ (the actual prices rose by $84 \%$ ); the rate of increase in housing prices in first tier cities more prominent, the Beijing rose $303 \%$ (the actual prices rose by $214 \%$ ), Shanghai rose $219 \%$ (the actual prices rose by 149\%), and Shenzhen rose $457 \%$ (the actual prices rose by $335 \%$ ); the real estate bubble serious. According to XianrongYi , an economist, he based on the real estate bubble index calculate that, 2009 - 2013, Chinese direct investment in real estate industry a total of 30.4 trillion RMB. If our government in 2008 and 2012 did not carry out the two property market stimulus, and assuming that our real estate market in self - regulation of prices, the real estate investment bubble ratio is 1, 2009 - 2013 increment in real estate investment should be 20 trillion RMB. From the mathematical analysis, the two stimulus policies of real estate investment directly resulted in a loss of 10.4 trillion RMB. Plus the multiplier effect of 3.15 , the whole social capital the total capital loss of up to 33 trillion RMB. Then another hypothesis, if the economic crisis, the growth of real estate investment is 0 , then the bubble index is 0 , then our real estate investment direct losses of 15.1 trillion RMB; if the financial crisis, the real estate investment growth in Europe and the United States, as negative growth, assuming bubble index is -1 , then our direct losses of 18.9 trillion RMBin real estate investment. Real estate bubble existence directly leads to serious economic losses.

\section{B. The Local Financial Revenue Over-Reliance on Real Estate.}

Support the local financial revenue mainly comes from the sale of land and real estate sales. In 2013, the national public finance revenue more than 12.9 trillion RMB, the national government fund revenue more than 5.2 trillion RMB. These two types of revenues reached 18.1 trillion RMB. Among them, from the land, real estate, construction of rent, tax and fee income totaled more than 6.6 trillion $\mathrm{RMB}$, accounting for the proportion of the national fiscal revenue totaled up to $36.5 \%$. In 2013 , the central public finance, government fund revenue total 6.4 trillion RMB, local fiscal two types ofrevenue total 11.7 trillion RMB. The largest contribution to local financial revenue is the transfer of state-owned land use rights, up to more than 4.1 trillion RMB in 2013, in more than 4 trillion RMB mark for the first time. This alone accounted for $35 \%$ of the total revenue of local public finance, government funds. Land, real estate, construction of the rental, tax, fee income, the vast majority of the local government, obviously, 6.6 trillion RMB from the land, the real estate, construction, contributed to local government with the more than $50 \%$ of the income. According to the Ministry of Finance announced the national fiscal revenue, in addition to 4.1 trillion RMBof land transfer income, from land, real estate, 
construction of the tax revenue reached 2.5 trillion RMB, approaching 2.88 trillion RMB of the Chinese largest tax -the domestic value-added tax contribution. In 2013, the general category of taxes, the real estate business tax revenue reached 541.1 billion RMB, an increase of $33.6 \%$, construction business tax $431.5 \%$ billion RMB, an increase of $16.5 \%$, the real estate enterprise income tax 285 billion $\mathrm{RMB}$, an increase of $25.1 \%$. In several base mainly for real estate taxes, income taxes for 384.4 billion RMB, an increase of $33.8 \%$, the land increment duty 329.4 billion RMB, an increase of $21.1 \%$, cultivated land usage tax 180.8 billion RMB, an increase of $11.6 \%$, urban land use tax 171.9 billion RMB, an increase of $11.5 \%$. National public finance revenue grew by $10.1 \%$ in 2013 . The real estate related tax revenue growth is more than the national public finance revenue. Visible local fiscal revenue depends on the extent of the real estate.

\section{Real Estate Construction Exist Waste of Land Resources.}

Real estate construction exist waste of land resources. First, the present situation of extensive utilization of land resources has not fundamentally changed. According to Shouzhi Wang, director general of the Department of policies and regulations of the Ministry of land after the "economical and intensive utilization of land", in accordance with the conference to disclose the data currently in Chinese town, inefficient land use accounted for more than $40 \%$, in the inefficient use of state of the mining towns construction about 5000 square kilometers, accounting for $11 \%$ of the national urban built-up area. The present situation of extensive utilization of land resources in china has not fundamentally changed. According to another data, in the process of urbanization in China, it is mainly used to build development zone industrial land accounted for an average of the urban land by $40 \%-50 \%$, accounting for $10 \%-15 \%$ which is far cry from the developed countries. Second, the existence of the land circle and not built, circle and slow construction, more than a few laps to build, and so on, causing the circle of good land wasted. Such as the Beijing ocean-wide hoard for 10 years of" Do nothing but have achievement". Up to 10 years after coming into the market, and ultimately profit or will exceed 40 billion RMB, the highest even close to 70 billion RMB. Another example of Shandong Mingshui economic development zone had a piece of area of 42 acres of land, idle for many years; recently invested by Shandong Kexing Bio-products Company built standard factory buildings, plant capacity utilization rate is only $2.25 \%$. By the circle and not build into circle and slow construction, little circle of building, the land utilization rate is very low. Third, demand excess for real estate speculation in big cities in a long term, hoarding houses, man-made waste of scarce land resources.

\section{Real Estate Commercial Housing Supply And Demand Structure is Seriously Unbalanced.}

A serious imbalance in the supply and demand structure of commercial real estate, on the one hand is the first city housing rigid demand, commercial housing prices rises all the way; on the other hand, the national commercial housing sales area is still inventory amazing. The third and fourth tier cities commercial housing prices continue to decline. In the macroeconomic stimulus policies, especially the role of loose monetary policy, the rapid digestion of the first tier cities inventory, housing prices adjustment appears strong rebound. The two three four line of the city inventory is still high, the slow recovery of the property market, since housing prices edged up or the continuation decline since the second quarter of 2014. By October 2015, first-tier cities house prices are down, the second or third-tier of the city house prices rise rateis still low. In 100 large and medium-sized cities, city of a gleam of chain price index rose $1.46 \%$ rose $13.75 \%$; second tier cities chain price index declined by $0.22 \%$, down $1.28 \%$; third tier cities housing prices index rose $0.05 \%$, fell $2.66 \%$. Among them, Beijing (Lou Pan), Shanghai (Lou Pan), Guangzhou (Lou Pan), Shenzhen (Lou Pan) four first-tier cities housing prices rose year on year in the country, especially in Shenzhen, prices rose amazing in 2015.

According to the National Bureau of statistics released January 20th, 2015 "The national real estate development and sales in 2014". Data show that in 2014, Chinese commercial housing sales area of 1.20649 billion square meters, down by $7.6 \%$ over the previous year, while the property market turnover in the history of the highest in 2013 , the figure for the growth of $17.3 \%$. Commercial housing sale of 7.6292 trillion RMB, down $6.3 \%$, while was an increase of $26.3 \%$ in 2013 . Among them, the residential sales fell by $7.8 \%$. According to E-House Chinese CEO Zuyu Ding, his analysis said that the national property market turnover of the whole show a trend of after the first suppression in 2014. Commercial housing sales area in2014 than in 2013 dropped $7.6 \%$, but is still the second highest in history, higher than the 1.113 billion square meters in 2012 . In terms of turnover, the property market continued to increase throughout the property. According to the National Bureau of statistics, senior economist Jianwei Liu analysis of commercial housing turnover, in December 2015, Beijing, Shanghai, Guangzhou, Shenzhen, four first-tier cities new commodity residential transactions growth are in more than $15 \%$, far higher than the national average. And according to the Swedish research center data, three or four lines of the city's overall turnover fell by $12 \%$ in 2013 , the imbalance of situation between supply and demand is obvious. National Bureau of statistics data shows that the country's commercial housing inventory is still high. By the end of 2014, the commodity house for sale area of 621.96 million square meters, compared to the end of November increased 23.74 million square meters, compared with an increase of 128.74 million square meters at the end of 2013. 


\section{COUNTERMEASURES AND SUGGESTIONS FOR CHINESE REAL ESTATE ECONOMIC PROBLEMS}

\section{A. Vigorously Develop the Real Economy, Focusing on the Increase of High Value-Added, High-Tech Industry \\ Investment, Improve The High-Tech Industry \\ Proportion in the National Economy.}

Solve Chinese real estate bubbles exist a serious problem, the key is that the state should attach great importance to the development of the real economy, the revitalization of the real economy. First of all, the national focus on high value-added, high-tech industry investment, improve the proportion of high-tech industry in the national economy; secondly, to reduce enterprise's economic burden, the low pay taxes, to reduce paid social security fees, reduce costs; to increase the profit of economic entities. Third, the state should formulate policies to strictly control the cost of real estate enterprises, reduce the profit space of real estate enterprises, thereby promoting social investment to the real economy investment. Fourth, the national bank to strictly control the scale of real estate credit, policy will increase the credit to the real economy, to develop the real economy.

\section{B. Reform the Current Financial System, Which gives Local More Fiscal and Taxation Authority, Increase Local Fiscal Revenue.}

On issues of local government finances over reliance on selling land and dependent on real estate, to reform the current fiscal system, tax distribution and classified fiscal system reform, give the local more taxation and fiscal rights, increase the local fiscal revenue. First of all, perfect the current local taxation system, adjust the structure of local tax system, increase the local main taxes, expand the scale of individual tax income, steadily improve the local individual tax revenue accounted for the proportion of local revenue; stable the local financial resource, fundamentally eliminate the problem of insufficient local revenue. Second, adjust the current tax refund policy. Central government provides local governments as part of budget expenditure, can through the tax return policy and the central special subsidies directly included in the scope of local finance revenue. Third, the central government should increase transfer payments. At present, the basic public service, compulsory education is mainly borne by the county finance, county-level local financial burden is heavy, even in the middle of the tax return to the local finance, county finance office is still difficult, so the central government should increase the transfer payment, basic public service, compulsory education expenditure borne by the central finance, may wish to consider in the form of special expenditure of transfer payments. In fact, the practice of basic public services abroad is to pay the bill by the state finance.

\section{In Accordance With The Law, Strengthen to Supervise and Manage the Land, The Reform of Land Management System, So That The Land Revenue Returns To Society.}

The reason for the land idle seems to be very complicatedly, in fact, all parts of the idle land source is soft, soft law enforcement system. So the government priority is to strengthen the land in accordance with the regulation, no matter what is corporate hoarding, for whatever reason also lead to unused land, should shall be the first to recover idle land, to investigate the reasons of idle land, the punishment of the penalty, the accountability of the accountability, the adjustment of the adjusting lenience. Second, we should reform the land management system. For the land system reform, it is to get rid of the state-owned urban and rural collective all these two unequal rights system, should be in the planning under the premise have equal access to urban construction and the right to make these two kinds of different ownership. It can not only solve the problem of the rights also solve the problem of space construction. At the same time with a part of the land to do a premium to solve the region's urban construction funding sources, the other part of the land to the original owners of the land through the appreciation of the benefits of urbanization. Third, the real income of the land from now owned by the government to return society, which is part of the land value increment through land value-added tax for the whole society to share.

\section{Equalization of Public Resources to Promote The Development Of Urbanization, Eliminate The Urban-Rural Dual Structure; Curb A, Second-Tier Cities Housing Investment Demand, Increase A, Second-Tier Cities Housing Construction.}

First-tier cities rigid demand of housing, commercial housing prices rise all the way in addition to the scarcity of land resources, developers profits high, the main reason is first-tier cities of high-quality public resources, infrastructure improvement, social security is superior, the high income jobs makes the first-tier cities net flow of population, caused the rigid demand for housing. The medium and small urban public resources are relatively poor, backward infrastructure, social security compared with the first-tier cities also have very big difference, less employment opportunities, the demand for housing is also small. For this reason, solve the problem of serious real estate commercial housing supply and demand structure imbalance to eliminate urban-rural dual structure. Firstly, t the government must carry on the construction of the equalization of public resources, increase infrastructure investment in medium and small cities, in order to improve the situation of poor infrastructure, at the same time, the central government fiscal backward area for financial transfer payment, special narrow the gap between the social security with the developed regions. Secondly, through the adjustment of industrial structure and distribution industry to the local small and medium-sized cities and areas surrounding the cities, increase of medium and small urban 
population more and more chances of employment. Thirdly, the reform of the household registration system, should adapt to the social security. Promote the development of urbanization and increase the demand for housing in small and medium-sized cities. Fourthly, the first-tier cities housing prices rise to control. On the one hand, we should limit the developers' profit. On the other hand, through measures to limit speculative housing profit, as soon as possible the introduction of property tax, real estate tax, levy rental housing tax, etc. Fifthly, the big city government to increase the construction of affordable housing, housing demand for low and middle income earners. Sixthly, the surrounding areas of super large cities to improve infrastructure, providing a complete public service, convenient transportation to the center of the city's population distribution,in order to solve the contradiction between supply and demand of housing in the main city.

\section{REFERENCES}

[1] Research of the role of real estate economy in China's national economic growth by XianchunXu etc. from Chinese Social Sciencesin 2015.1st

[2] Explore the macro control of real estate economy in China by NaZhuo andZhongze from Technical Economics and Managementin 2015. $6^{\text {th }}$

[3] Explore the coordination of real estate economy and market economy by Haixia HuangChang from Technical Economics and Management in 2015.6 th $^{\text {-iii }}$

[4] Causes of the economic risks and real estate bubble Candice Strategies by HongWang fromFinancial Timesinlate 2013.11 